\title{
Tyrosinemia type I: long-term outcome in a patient treated with doses of NTBC lower than recommended
}

\author{
Patrizia D'Eufemia • Mauro Celli • Martina Tetti • \\ Roberto Finocchiaro
}

Received: 24 November 2010 / Accepted: 3 February 2011 / Published online: 22 February 2011

(C) Springer-Verlag 2011

Sir,

The paper by El-Karasky et al. "NTBC therapy for tyrosinemia type 1: how much is enough?" raises the question if doses of nitisinone (NTBC) lower than recommended could be effective in the treatment of tyrosinemia type 1 [1]. The authors report that the duration of follow-up, which does not exceed 27 months, represents a limitation of their study. We follow a 15 -year-old male patient with tyrosinemia type 1 diagnosed at 6 months of age and promptly enrolled in an NTBC trial [2]. He started treatment with the recommended average dose of $1 \mathrm{mg} / \mathrm{kg} /$ day divided in two doses. After 2 months of treatment, plasma and urinary succinylacetone were undetectable. An improvement in hepatic function was noted within 18 months and serum alpha-fetoprotein progressively decreased and normalized after 24 months. Before starting NTBC therapy, the hepatic ultrasonography showed multiple cirrhotic nodules that disappeared after 48 months of treatment. Our patient thrived well but corneal opacities occurred, when tyrosine levels exceeded $700 \mu \mathrm{mol} / \mathrm{l}$ because of dietary noncompliance. After 114 months of treatment, based on clinical and biochemical follow-up, we progressively reduced the NTBC dose to the actual dose of $0.55 \mathrm{mg} / \mathrm{kg} /$ day. The NTBC serum concentration always remained above the recommended level of $30 \mu \mathrm{mol} / 1$ and urinary succinylacetone remained undetectable.

Until now, the patient is in good condition with normal growth and absence of biochemical and ultrasound evidence of liver injury. Our case suggests that doses of NTBC, lower than recommended, could be effective in the long-term outcome.

Conflict of interest None.

\section{References}

1. El-Karaksy H, Rashed M, El-Sayed R, El-Raziky M, El-Koofy N, El-Hawary M, Al-Dirbashi O (2010) NTBC therapy for tyrosinemia type 1: how much is enough? Eur J Pediatr 169:689-693

2. Holme E, Lindstedt S (1998) Tyrosinaemia type 1 and NTBC (2-(2nitro-4-trifluoromethylbenzoyl)-1, 3-cyclohexanedione). J Inherit Metab Dis 21:507-517
P. D’Eufemia $(\bowtie) \cdot$ M. Celli $\cdot$ M. Tetti $\cdot$ R. Finocchiaro Department of Pediatrics, "La Sapienza" University of Rome, Via Regina Elena 324,

00161 Rome, Italy

e-mail: patdeufemia@inwind.it 